\title{
The impact of gender on long-term mortality in patients with multivessel disease after primary percutaneous coronary intervention
}

\author{
S. Ghauharali-Imami $\cdot$ M. Bax $\cdot$ A. Haasdijk $\cdot$ C. Schotborgh $\cdot$ \\ P. Oemrawsingh $\cdot$ J. Bech $\cdot$ R. van Domburg $\cdot$ F. Zijlstra
}

Published online: 8 October 2015

(C) The Author(s) 2015. This article is published with open access at Springerlink.com

\begin{abstract}
Background Gender and complete revascularisation are known to affect mortality. The objective of this study was to analyse a gender difference in mortality with respect to complete revascularisation for multivessel disease after primary percutaneous coronary intervention (PPCI) in STelevation myocardial infarction (STEMI) patients.

Method In a prospective consecutive cohort of 1472 patients presenting with STEMI for PPCI, between January 2006 and January 2010, 832 patients with multivessel disease were analysed. The primary outcome was long-term mortality.

Results Median follow-up was $3.3 \pm 1.2$ years. Complete revascularisation was performed less in females than in males ( 30 vs. $38 \%$; $p=0.04)$. At PPCI, women $(27 \%, n=221)$ were \pm 10 years older $(p=0.001)$, had more hypertension, renal failure and symptoms of heart failure (all $p<0.01)$. Cumulative long-term mortality with incomplete revasculari-
\end{abstract}

\footnotetext{
S. Ghauharali-Imami $(\bowtie) \cdot$ M. Bax $\cdot$ A. Haasdijk

C. Schotborgh

Haga-Teaching Hospital, HagaZiekenhuis,

Leyweg 275,

2545 CH The Hague, The Netherlands

e-mail: sh.imami@hagaziekenhuis.nl

P. Oemrawsingh

Medical Centre Haaglanden,

The Hague, The Netherlands

J. Bech

Reinier de Graaf Gasthuis,

Delft, The Netherlands

R. van Domburg $\cdot$ F. Zijlstra

Erasmus MC,

Rotterdam, The Netherlands
}

sation was higher in females (F: 30 vs. M: $15 \%, p=0.01$ ). After adjustment for baseline characteristics, complete revascularisation $(0.84 ; 95 \%$ CI $0.54-1.32)$ and gender (1.11; 95\% CI 0.73-1.69) lost significance. Also the gender-bycomplete revascularisation interaction was not significant at long term. In women, age under 60 years independently predicted higher mortality (HR 10.09; 95\% CI 3.08-33.08; $p<0.001)$.

Conclusion In STEMI patients with multivessel disease at PPCI, women under the age of 60 years had higher mortality, but in women older than 60 years comorbidity impacted the outcome of revascularisation strategy in the long term.

Keywords ST-elevation myocardial infarction - Gender · Complete revascularisation $\cdot$ Mortality

\section{Introduction}

Gender and revascularisation strategy (complete vs. incomplete revascularisation) are factors known to affect mortality in patients with ST-elevation myocardial infarction (STEMI) and multivessel disease [1-3]. Evidence of a higher mortality in females dates back to the fibrinolysis era [4], particularly in patients presenting with STEMI (20 vs. $8 \%, p=0.029)[4,5]$. Compared with fibrinolysis, a primary percutaneous coronary intervention (PPCI) has been proven to be a better reperfusion strategy [6], especially for women [7-9]. Some researchers ascribe the higher mortality in women presenting with STEMI to higher age and more comorbidity at presentation or to less effective treatment and fewer drug-eluting stents $[7,10]$. Others found gender to be an independent predictor for mortality [11].

Currently, the optimal revascularisation strategy for multivessel disease is a matter of debate $[3,12]$ and the impact 
of gender has not been investigated yet. Therefore, the objective of this study was to investigate long-term mortality in relation to complete revascularisation for multivessel disease in males and females with PPCI for STEMI. Furthermore, possible interactions for gender-by-treatment strategy and gender-by-age for mortality were analysed in this patient group.

\section{Methods}

From January 2006 to January 2010, 1472 consecutive patients were prospectively registered with PPCI for STEMI [13, 14], of whom 997 (50\%) had multivessel disease. According to local protocol, all patients with multivessel disease, except for patients with multivessel PCI (7\%), were adjudicated for revascularisation strategy by the 'heart team' ( $93 \%$, at least one interventional cardiologist and one heart surgeon). Multivessel disease was defined as $>50 \%$ diameter stenosis by visual estimate in one or more nonculprit epicardial coronary arteries or their major branches on PPCI angiography. Patients with isolated left main coro- nary stenosis were classified as having two-vessel disease. Patients with prior coronary artery bypass graft (CABG), cardiogenic shock, an intra-aortic balloon pump, mechanical ventilation or resuscitation at presentation for PPCI were excluded $(n=165 ; 17 \%)$. As presented in Fig. 1 , the remaining $832(56 \%)$ patients with multivessel disease were analysed according to gender and revascularisation strategy: incomplete revascularisation, in which only the culprit lesion was treated at PPCI versus complete revascularisation of all significant non-culprit lesions during the PPCI procedure or in a staged session (PCI: median; 18 days, IQR: 12-40 days or CABG: median; 16 days, IQR 8-46 days).

\section{Clinical variables}

Hospital records and angiographic images were reviewed for procedural data and clinical variables including age, gender, smoking habit, use of medication or history of diabetes, hypertension, hypercholesterolaemia, previous STEMI, previous PCI or CABG, renal failure (glomerular
Fig. 1 Flowchart of patient inclusion and revascularisation strategy for multivessel disease according to gender after primary percutaneous coronary intervention for ST-elevation myocardial infarction

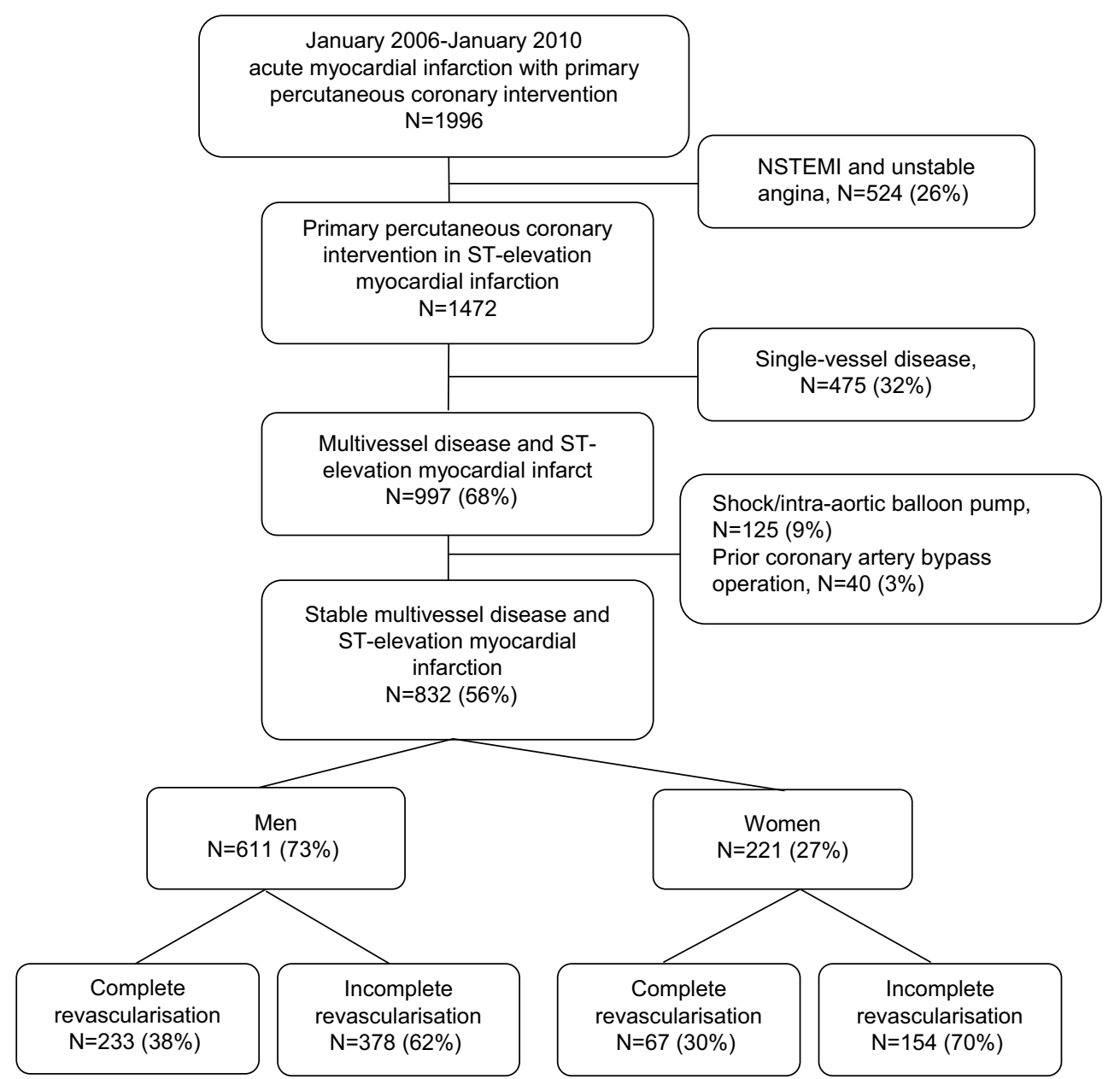


filtration rate (GFR) $<30 \mathrm{ml} / \mathrm{min}$ ) at the time of presentation for PPCI. During follow-up, data on repeat revascularisation (PCI or $\mathrm{CABG})$, recurrent myocardial infarction, occurrence of cerebrovascular accidents and mortality were recorded. Mortality was verified at the Dutch national population registry ('Statistics Netherlands') in The Hague. Follow-up was achieved in hospital in $100 \%$ and during follow-up in $99 \%$, as only $1 \%$ of patients migrated.

\section{Medical treatment from ambulance to catheterisation laboratory}

All patients presenting within $6 \mathrm{~h}$ from the onset of symptoms with STEMI received a loading dose of clopidogrel $600 \mathrm{mg}$ orally, acetylsalicylic acid (250 mg intravenously or $300 \mathrm{mg}$ orally) and $5000 \mathrm{IU}$ heparin at first medical contact (either in the ambulance or at the emergency room). The use of glycoprotein IIb-IIIA inhibitors and/or low-molecular-weight heparin before, during or after PPCI was at the operator's decision. A procedure was considered successful when $<20 \%$ of residual stenosis was achieved by balloon angioplasty or stent deployment at the culprit lesion, with Thrombolysis in Myocardial Infarction (TIMI) grade 3 flow.

\section{Discharge medication}

After PPCI, clopidogrel $75 \mathrm{mg} /$ day was maintained for at least 12 months and acetylsalicylic acid $80 \mathrm{mg}$ /day indefinitely. Further prescription was left to the treating cardiologist.

\section{Endpoints}

The main purpose of this study was to investigate long-term mortality in relation to complete revascularisation for multivessel disease in males and females with PPCI for STEMI. Furthermore, possible interactions for gender-by-treatment strategy and gender-by-age for mortality were analysed in this patient group.

\section{Statistical analysis}

Quantitative data are expressed as mean \pm SD and nominal data as frequencies followed by percentages $(n ; \%)$. Data were checked for a normal distribution and analysed by either the independent sample T-test or Chi-square test when applicable. Nominal data were analysed using a Chi-square test or a Mann-Whitney U test when appropriate. Data with a normal distribution are presented as mean \pm standard devi- ation and skewed data as median with interquartile range (IQR) 25th-75th percentile. Data are censored at end of life or end of follow-up (September 2012). Crude mortality was analysed by the Kaplan-Meier method using the logrank test. Logistic regression was used for the analysis of in-hospital mortality. Proportional Cox regression analysis was utilised for 1-year and long-term mortality in women versus men and was expressed as a hazard ratio with $95 \%$ confidence interval followed by significance (HR; $95 \% \mathrm{CI}$, $p$-value). All baseline characteristics were at first analysed in the univariate and secondly only the most significant characteristics were added to gender and treatment strategy in the multivariate analysis according to a maximum of $10 \%$ of the number of in-hospital events (1 event; age), at 1-year (4 events; age, time to first medical contact, renal failure at admission (GFR $<0.30 \mathrm{ml} / \mathrm{mmol}$ ), procedural success) and in the long-term ( 7 events; age, time to first medical contact, renal failure at admission (GFR $<0.30 \mathrm{ml} / \mathrm{mmol}$ ), procedural success, previous acute myocardial infarction, positive family history, hypertension). Age was analysed according to categories of 5 years, starting from 40 years of age (less than 40 vs. more than 40 years, etc.) and stratified to gender.

All tests were two-sided, a $p$-value $<0.05$ was considered statistically significant. Statistical analysis was performed using SPSS statistical software for Windows.

\section{Results}

As presented in Table 1, women were significantly older $(71.2 \pm 12.1$ vs. $61.8 \pm 12.3, p<0.001)$, more often had hypertension, symptoms of heart failure and renal failure at admission than men (all $p<0.01$ ). Smoking, familial predisposition, and previous PCI were more frequent in men (all $p<0.05$ ). Previous STEMI and median time from symptom to first medical contact was comparable between genders. Complete revascularisation for multivessel disease was more frequent in men than in women ( 38 vs. $30 \%, p=0.04$ ). There was an equal distribution of two- and three-vessel disease, culprit and non-culprit lesions. During PPCI, glycoprotein IIb-IIIa inhibitors were more often used in males than in females ( 62 vs. $72 \%, p=0.005)$. No significant gender difference was shown for TIMI flow pre- or post-PPCI, the number of stents placed and the stent length. However, the diameter of the stent was smaller in females than in males ( 3.01 vs. $3.15 \mathrm{~mm}, p=0.002$ ).

\section{Mortality}

As presented in Fig. 2, in-hospital mortality was similar in men and women (M: 2 vs. F: $3 \%, p=0.27$ ). In the long- 
Table 1 Baseline and procedural characteristics of ST-elevation myocardial infarct patients with multi-vessel disease at primary percutaneous intervention

\begin{tabular}{|c|c|c|c|}
\hline Baseline characteristics $N(\%)$ & Female $(n=221 ; 27 \%)$ & Male $(n=611 ; 73 \%)$ & $P$ \\
\hline Age $($ mean $\pm \mathrm{SD})$ & $71.2 \pm 12.1$ & $61.8 \pm 12.3$ & 0.001 \\
\hline Diabetes mellitus & $46(21)$ & $128(21)$ & NS \\
\hline Hypercholesterolaemia & $54(24)$ & $126(21)$ & NS \\
\hline History renal failure & $7(3)$ & $17(3)$ & NS \\
\hline Hypertension & $111(50)$ & $223(37)$ & $<0.001$ \\
\hline Family history & $66(30)$ & $233(38)$ & 0.03 \\
\hline Smoker & $71(32)$ & $259(42)$ & 0.008 \\
\hline Symptoms of heart failure & $15(7)$ & $16(3)$ & 0.005 \\
\hline Previous percutaneous coronary intervention & $10(5)$ & $53(9)$ & 0.046 \\
\hline Previous acute myocardial infarction & $17(8)$ & $47(8)$ & NS \\
\hline GFR $<0.30 \mathrm{ml} / \mathrm{mmol}$ at presentation & $58(29)$ & $80(14)$ & $<0.001$ \\
\hline \multicolumn{4}{|l|}{ Procedural characteristics $n(\%)$} \\
\hline \multicolumn{4}{|l|}{ Median; 25th-75th percentile } \\
\hline Symptom-first medical contact (hours) & 1:42.(1:00-4:00) & $1: 33(0: 45-3: 06)$ & 0.08 \\
\hline First medical contact-needle (hours) & $0: 35 .(0: 10-1: 13)$ & $0: 30(0: 10-1: 15)$ & 0.40 \\
\hline Needle-balloon (hours) & $0: 15(0: 11-0: 21)$ & $0: 16(0: 11-0: 22)$ & 0.52 \\
\hline Incomplete revascularisation & $154(70)$ & $378(62)$ & 0.04 \\
\hline Complete revascularisation after PPCI & $67(30)$ & $233(38)$ & \\
\hline 1-stage PCI & $11(4)$ & $50(8)$ & NS \\
\hline 2-stage PCI & $28(13)$ & $95(16)$ & NS \\
\hline CABG & $28(13)$ & $88(14)$ & NS \\
\hline Three-vessel disease & $114(51)$ & $294(48)$ & NS \\
\hline \multicolumn{4}{|l|}{ Culprit } \\
\hline Left anterior descending & $87(39)$ & $219(36)$ & NS \\
\hline Right coronary artery & $100(45)$ & $262(43)$ & NS \\
\hline Left circumflex & $32(15)$ & $123(21)$ & NS \\
\hline Left main & $1(1)$ & $0(0)$ & NS \\
\hline \multicolumn{4}{|l|}{ Non-culprit } \\
\hline Left anterior descending & $109(49)$ & $329(54)$ & NS \\
\hline Right coronary artery & $84(38)$ & $224(37)$ & NS \\
\hline Left circumflex & $133(60)$ & $343(56)$ & NS \\
\hline Left main & $35(6)$ & $18(8)$ & NS \\
\hline Glycoprotein IIb/IIIa inhibitor & $133(62)$ & $432(72)$ & 0.005 \\
\hline \multicolumn{4}{|l|}{ TIMI-flow pre-primary percutaneous intervention } \\
\hline 0 & $141(64)$ & $435(71)$ & NS \\
\hline 1 & $33(15)$ & $68(11)$ & \\
\hline 2 & $32(15)$ & $78(13)$ & \\
\hline 3 & $15(7)$ & $30(5)$ & \\
\hline \multicolumn{4}{|c|}{ TIMI-flow post- primary percutaneous intervention } \\
\hline 0 & $5(2)$ & $6(1)$ & NS \\
\hline 1 & $7(3)$ & $8(1)$ & \\
\hline 2 & $17(8)$ & $53(9)$ & \\
\hline 3 & $192(87)$ & $544(89)$ & \\
\hline Procedural success & $185(84)$ & $521(85)$ & NS \\
\hline Drug-eluting stent & $86(40)$ & $196(32)$ & NS \\
\hline Bare metal stent & $132(60)$ & $411(68)$ & 0.04 \\
\hline Total number of stents & $1.45 \pm 0.91$ & $1.46 \pm 0.83$ & NS \\
\hline Diameter stents & $3.01 \pm 0.51$ & $3.15 \pm 0.52$ & 0.002 \\
\hline Length of stent & $19.9 \pm 7.8$ & $20.7 \pm 8.3$ & NS \\
\hline
\end{tabular}

term, cumulative mortality was higher in women than in men (at 1 year: 8 vs. $4 \%, p=0.009$ and at long-term: 13 vs. $7 \%, p=0.004)$. Overall, complete revascularisation resulted in lower cumulative mortality than incomplete revascularisation (in-hospital: 1 vs. $3 \%, p=0.009$, at 1 -year: 2 vs. $6 \%$, $p=0.007$ and long term: 7 vs. $10 \%, p=0.08$ ). 


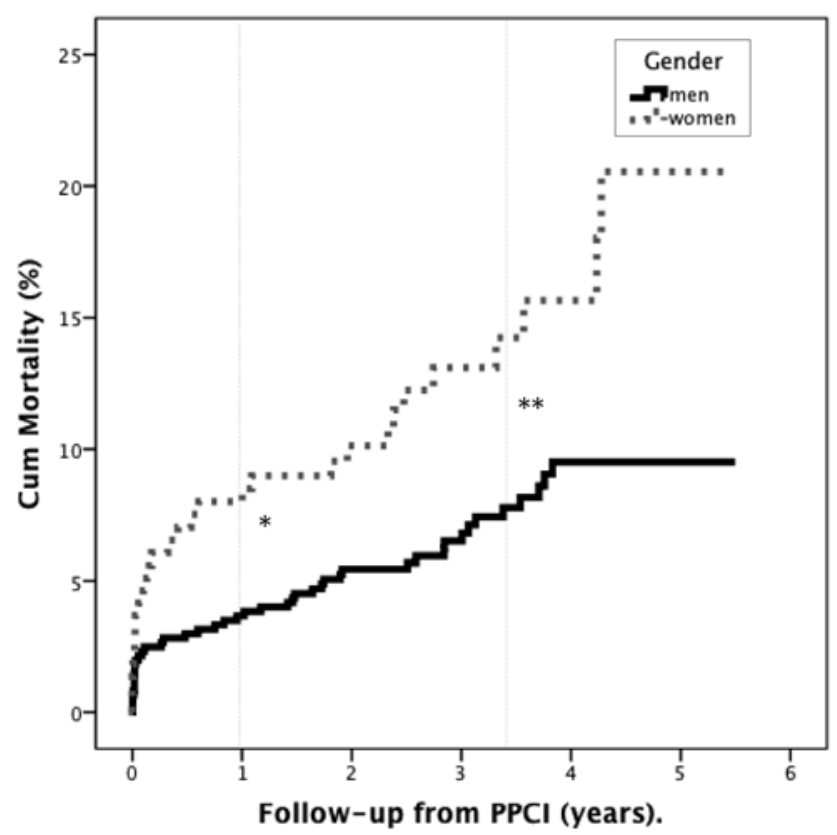

Fig. 2 Long-term mortality in male and female patients with multivessel disease after primary PCI for ST-elevation myocardial infarction. A significantly higher mortality in women was shown at 1-year, ${ }^{*} p=0.009$ and at long term, ${ }^{* *} \mathrm{p}=0.004$

\section{Mortality in females vs. males according to treatment strategy}

As shown in Table 2, in women no significant difference for mortality was shown between complete or incomplete revascularisation during follow-up, whereas in men a significantly lower mortality was shown for complete revascularisation in hospital $(p<0.001)$.

\section{Mortality in females vs. males according to treatment strategy}

As presented in Fig. 3, complete revascularisation had higher in-hospital mortality in females than in males $(p=0.005)$, but similar long-term mortality. Incomplete revascularisation had comparable in-hospital mortality between genders, but higher cumulative 1-year and long-term mortality in females.

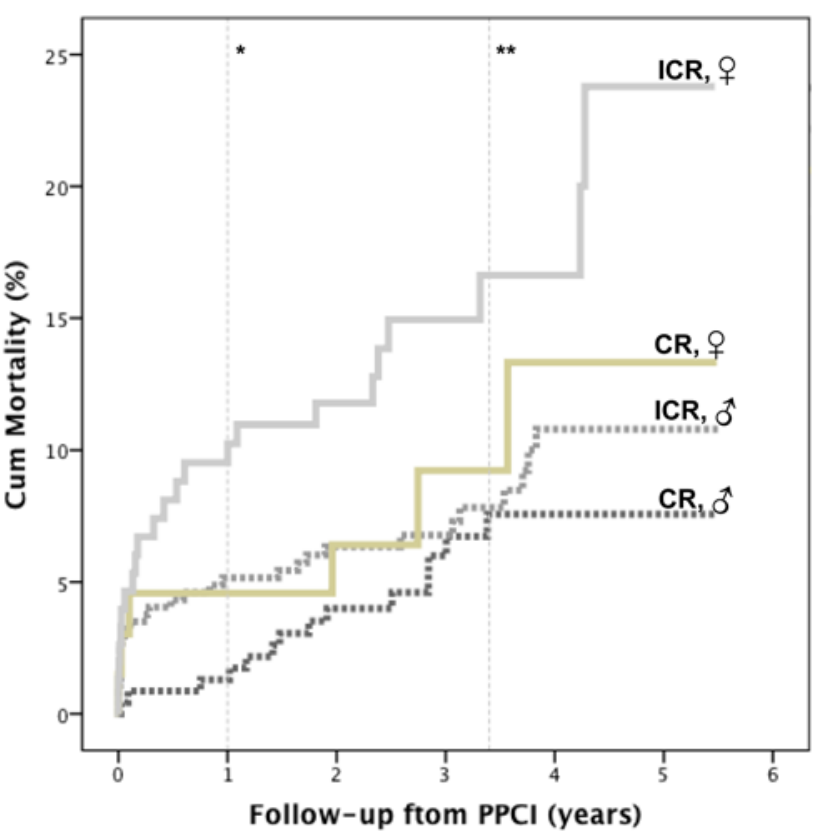

Fig. 3 Mortality according to treatment strategy in females and males. Kaplan-Meier: in the long term women benefit more from complete than from incomplete revascularisation, at 1 year*, $p=0.05$ and at long term ${ }^{* *}, p=0.01 ; C R$ complete revascularisation, $I C R$ incomplete revascularisation, $\hat{O}$ male, $q$ female

\section{Mortality in females vs. males according to age}

A significant gender disparity in age at presentation for PPCI was shown in our analysis (Table 1). As presented in Fig. 4, when mortality in men was compared with women of a similar age, higher mortality was shown in women under the age of 60 years.

\section{Univariate analysis}

As presented in Table 3, complete revascularisation had lower mortality than incomplete revascularisation during follow-up, however not in hospital. Females had higher mortality than males at 1 -year and also in the long term. The interaction of complete revascularisation-by-gender and age-by-gender was not significant $(p=0.73)$. The interac-

Table 2 Cumulative data from Kaplan-Meier analysis with $p$-values according to the log-rank test in females versus males for treatment strategy during follow-up

\begin{tabular}{|c|c|c|c|c|c|c|c|c|}
\hline \multirow{2}{*}{$\begin{array}{l}\text { Cumulative } \\
\text { mortality } \\
\text { Gender }\end{array}$} & \multicolumn{3}{|c|}{ Complete revascularisation (CR) } & \multicolumn{3}{|c|}{ Incomplete revascularisation (ICR) } & \multirow{2}{*}{$\begin{array}{l}\begin{array}{l}\text { ICR vs. CR } \\
\text { in females }\end{array} \\
P\end{array}$} & \multirow{2}{*}{$\begin{array}{l}\text { ICR vs. CR } \\
\text { in males } \\
P\end{array}$} \\
\hline & $\begin{array}{l}\text { Female }(\% \text {, number } \\
\text { of events) }\end{array}$ & $\begin{array}{l}\text { Males (\%, num- } \\
\text { ber of events) }\end{array}$ & $P$ & $\begin{array}{l}\text { Females (\%, } \\
\text { number of events) }\end{array}$ & $\begin{array}{l}\text { Males (\%, num- } \\
\text { ber of events) }\end{array}$ & $P$ & & \\
\hline In-hospital & $5 \%(3)$ & $0 \%(1)$ & 0.005 & $3 \%(4)$ & $3 \%(10)$ & 0.65 & 0.46 & $<0.001$ \\
\hline 1-year & $5 \%(3)$ & $1 \%(3)$ & 0.11 & $9 \%(19)$ & $5 \%(14)$ & 0.05 & 0.24 & 0.02 \\
\hline Long-term & $9 \%(6)$ & $6 \%(14)$ & 0.32 & $15 \%(23)$ & $8 \%(30)$ & 0.01 & 0.23 & 0.30 \\
\hline
\end{tabular}


Table 3 Univariate and multivariate analysis for mortality according to gender and treatment strategy adjusted for; in-hospital: age at primary percutaneous intervention, at 1-year adjusted also for time to first medical contact, renal failure at admission (GFR $<0.30 \mathrm{ml} / \mathrm{mmol}$ ), TIMI-flow post procedure and at long-term also for previous acute myocardial infarction, positive family history, hypertension

\begin{tabular}{|c|c|c|c|c|c|c|c|c|c|c|c|c|}
\hline & In-hospita & & & & 1-year & & & & Long-term & & & \\
\hline & $\begin{array}{l}\text { Univari- } \\
\text { ate } \mathrm{HR} \text {; } \\
95 \% \mathrm{CI}\end{array}$ & $P$ & $\begin{array}{l}\text { Multivar- } \\
\text { iate HR; } \\
95 \% \mathrm{CI}\end{array}$ & $P$ & $\begin{array}{l}\text { Univari- } \\
\text { ate } \mathrm{HR} \text {; } \\
95 \% \mathrm{CI}\end{array}$ & $P$ & $\begin{array}{l}\text { Multi- } \\
\text { variate } \\
\text { HR; } \\
95 \% \text { CI }\end{array}$ & $P$ & $\begin{array}{l}\text { Univari- } \\
\text { ate } \mathrm{HR} \text {; } \\
95 \% \mathrm{CI}\end{array}$ & $P$ & $\begin{array}{l}\text { Multivari- } \\
\text { ate } \mathrm{HR} ; \\
95 \% \mathrm{CI}\end{array}$ & $P$ \\
\hline Female gender & $\begin{array}{l}1.78 ; \\
0.68-4.66\end{array}$ & 0.24 & $\begin{array}{l}0.91 ; \\
0.33-2.54\end{array}$ & 0.86 & $\begin{array}{l}2.30 \\
1.21-4.35\end{array}$ & 0.01 & $\begin{array}{l}1.13 ; \\
0.52-2.43\end{array}$ & 0.76 & $\begin{array}{l}2.29 \\
1.59-3.31\end{array}$ & $<0.001$ & $\begin{array}{l}1.11 ; \\
0.73-1.69\end{array}$ & 0.63 \\
\hline $\begin{array}{l}\text { Complete } \\
\text { revascularisa- } \\
\text { tion }\end{array}$ & $\begin{array}{l}0.50 ; \\
0.16-1.53\end{array}$ & 0.23 & $\begin{array}{l}0.62 ; \\
0.20-1.94\end{array}$ & 0.41 & $\begin{array}{l}0.32 ; \\
0.14-0.77\end{array}$ & 0.01 & $\begin{array}{l}0.36 ; \\
0.13-0.95\end{array}$ & 0.04 & $\begin{array}{l}0.63 ; \\
0.42-0.94\end{array}$ & 0.02 & $\begin{array}{l}0.84 ; \\
0.54-1.32\end{array}$ & 0.45 \\
\hline $\begin{array}{l}\text { Age at primary } \\
\text { PCI }\end{array}$ & $\begin{array}{l}1.08 ; \\
1.04-1.12\end{array}$ & $<0.001$ & $\begin{array}{l}1.08 ; \\
1.03-1.12\end{array}$ & 0.001 & $\begin{array}{l}1.08 ; \\
1.06-1.12\end{array}$ & $<0.001$ & $\begin{array}{l}1.05 ; \\
1.02-1.09\end{array}$ & 0.002 & $\begin{array}{l}1.08 ; \\
1.07-1.10\end{array}$ & $<0.001$ & $\begin{array}{l}1.07 ; \\
1.05-1.09\end{array}$ & $<0.001$ \\
\hline
\end{tabular}

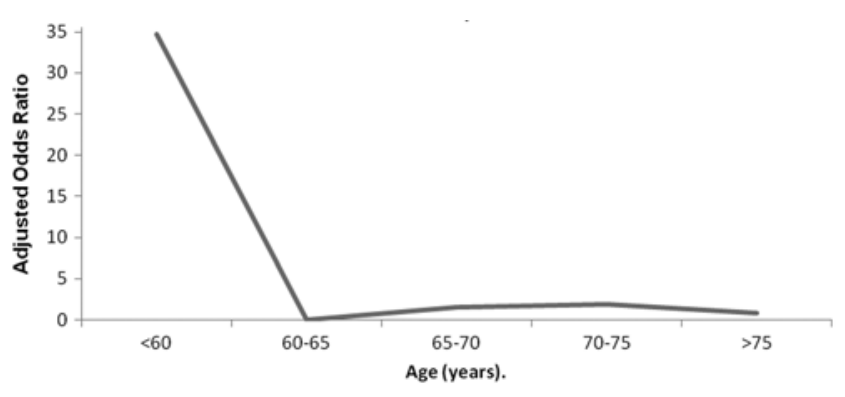

Fig. 4 Age-adjusted long-term mortality in women compared with men at long-term follow-up. Females under the age of 60 years had a significantly higher mortality rate compared with males of a similar age

tion of age 60 years-by-gender was significant at 1-year and in the long term only ( $p=0.03$ and $p=0.002$, respectively).

\section{Multivariate analysis}

As shown in Table 3, after adjustment for baseline characteristics gender no longer predicted mortality and complete revascularisation was only associated with 1 -year morality. The interaction for age under 60 years-by-gender $(p=0.006)$ showed a higher mortality rate in females than in males under the age of 60 years in the long term, independent of risk profile (HR 10.09; $95 \%$ CI 3.08-33.08, $p<0.001$ ).

\section{Discussion}

The main finding of our long-term analysis was that females benefit from complete revascularisation equally to males. In addition, incomplete revascularisation had higher mortality in females than in males in the long term. However, significance was lost after adjustment for baseline characteristics. In addition, the gender-by-complete revascularisation and gender-by-age interaction was not significant in the long term. However, when mortality was analysed between genders according to age, a significantly higher mortality was shown in females compared with males under the age of 60 years, independent of risk profile.

This is an important topic because recent literature has shown better clinical outcome with complete revascularisation in patients with multivessel disease [3]. This is also underlined by the Culprit study, with a lower rate of the composite endpoint in patients with complete revascularisation (HR: 0.45 ; 95\% CI: $0.24-0.84$; $p=0.009$ ) [15]; however, no significance was shown for mortality. Our analysis shows an overall lower mortality with complete revascularisation. However, complete revascularisation was performed significantly less often in women than in men, whereas no significant difference was shown for three-vessel disease, culprit or non-culprit lesions. In addition, incomplete revascularisation had higher long-term mortality in females than in males. Previous research has shown less aggressive management strategies with lower frequencies of PCI and less aggressive medical treatment in women [16, 17]. Women in our analysis had smaller vessels and more often renal failure at admission and this might have complicated a complete revascularisation strategy. According to Gevaert et al. [18] renal failure at admission is an independent predictor for in-hospital mortality, however with similar impact between genders.

The unadjusted mortality was higher in women during follow-up, but reduced significantly after adjustment for risk profile. This is in accordance with recent research [1, 19-21], and underlines the importance of aggressive management of comorbidity during follow-up. In a metaanalysis involving 18,555 women with STEMI and PPCI, Pancholy et al. found a nearly twofold higher risk for mortality in women in hospital, which was significantly attenuated when adjusted for baseline cardiovascular risk factors and clinical profile [22]. In contrast to Pancholy et al., in our analysis in-hospital mortality was similar between genders. 
This was also shown in other research $[1,10]$ and largely explained by equal symptom to first medical contact, first medical contact-to-needle and needle-to-balloon times in men and women in our cohort [23, 24]. Furthermore, the homogenous patient cohort, with the exclusion of cardiac shock patients and the prerequisite of a PPCI in order to enter our analysis, might also have reduced a gender difference for in-hospital mortality [25].

Further, a significantly higher age at admission in females was noticed in our analysis and also shown in previous studies. A protective effect of oestrogens has been suggested to explain the older age and higher risk profile at presentation for PPCI in females [26].

A comparison between mortality in men and women of similar age showed a higher mortality rate in females than in males under the age of 60 years, independent of risk profile. A higher mortality in younger women was also shown in previous studies [1, 27-29].

\section{Limitations}

A possible selection bias was minimised in our study as the revascularisation strategy for non-culprit lesions was decided by the 'heart team' (including at least one cardiologist and one heart surgeon) in $93 \%$ of patients and was not subject to an individual opinion. Furthermore, with the exclusion of cardiac shock and previous $\mathrm{CABG}$, a homogenous cohort was analysed and these limits strengthen our database. Moreover, shock is inherently related to a higher mortality, especially in women with STEMI [23-25]. Also patients were followed-up for $3.3 \pm 1.2$ years, and this increases our power. We tried to adjust for important confounders with either logistic or Cox regression analysis. However, the number of events in our cohort limited us in the number of confounders we could adjust for. Although we assent to the importance of bleeding complications in females at PPCI and its possible influence on mortality, it was not included in our database. Medical treatment in hospital was according to protocol; however the medication at discharge was not listed in our database and might have influenced long-term mortality. In summary, our cohort represents contemporary clinical practice and although no definitive conclusions can be drawn, we were able to present equal benefit from complete revascularisation compared with higher mortality risk with incomplete revascularisation in women than in men in the long term. This study emphasises the need for a large prospective randomised trial with the power to investigate and specify optimal treatment strategy and timing of revascularisation in women with multivessel disease presenting with STEMI for PPCI.

\section{Conclusion}

In STEMI patients with multivessel disease at PPCI, women under the age of 60 years had higher mortality, but in women older than 60 years comorbidity impacted outcome of revascularisation strategy in the long term.

Acknowledgment We would like to thank R.T. van Domburg of Erasmus Medical Centre for his work and help with the statistical analysis and review of this article and Drs. S. Hamel-Brown for her support in English writing.

Funding None.

\section{Conflict of interest None declared.}

Open Access This article is distributed under the terms of the Creative Commons Attribution License which permits any use, distribution, and reproduction in any medium, provided the original author(s) and the source are credited.

\section{References}

1. Jackson EA, Moscucci M, Smith DE, et al. The association of sex with outcomes among patients undergoing primary percutaneous coronary intervention for ST elevation myocardial infarction in the contemporary era: insights from the Blue Cross Blue Shield of Michigan Cardiovascular Consortium (BMC2). Am Heart J. 2011;161:106-12.

2. D'Ascenzo F, Gonella A, Quadri G, et al. Comparison of mortality rates in women versus men presenting with ST-segment elevation myocardial infarction. Am J Cardiol. 2011;107:651-4.

3. Wald DS, Morris JK, Wald NJ, et al. Randomized trial of preventive angioplasty in myocardial infarction. $\mathrm{N}$ Engl $\mathrm{J}$ Med. 2013;369:1115-23.

4. Weaver WD, White HD, Wilcox RG, et al. Comparisons of characteristics and outcomes among women and men with acute myocardial infarction treated with thrombolytic therapy. GUSTO-I investigators. JAMA. 1996;275:777-82.

5. Hochman JS, Tamis JE, Thompson TD, et al. Sex, clinical presentation, and outcome in patients with acute coronary syndromes. Global Use of Strategies to Open Occluded Coronary Arteries in Acute Coronary Syndromes IIb Investigators. N Engl J Med. 1999;341:226-32.

6. Keeley EC, Boura JA, Grines CL. Primary angioplasty versus intravenous thrombolytic therapy for acute myocardial infarction: a quantitative review of 23 randomised trials. Lancet. 2003;361:13-20.

7. De Luca G, Suryapranata H, Dambrink JH, et al. Sex-related differences in outcome after ST-segment elevation myocardial infarction treated by primary angioplasty: data from the Zwolle Myocardial Infarction study. Am Heart J. 2004;148:852-6.

8. Mallik S, Vaccarino V. Outcomes of thrombolytic therapy for acute myocardial infarction in women. Prog Cardiovasc Dis. 2004;47:58-71.

9. Motovska Z, Widimsky P, Aschermann M. The impact of gender on outcomes of patients with ST elevation myocardial infarction transported for percutaneous coronary intervention: analysis of the PRAGUE-1 and 2 studies. Heart. 2008;94:e5. 
10. Wijnbergen I, Tijssen J, ’t Veer M van, et al. Gender differences in long-term outcome after primary percutaneous intervention for ST-segment elevation myocardial infarction. Catheter Cardiovasc Interv. 2013;82:379-84.

11. Benamer H, Tafflet M, Bataille S, et al. Female gender is an independent predictor of in-hospital mortality after STEMI in the era of primary PCI: insights from the greater Paris area PCI Registry. EuroIntervention. 2011;6:1073-9.

12. Iqbal MB, Ilsley C, Kabir T, et al. Culprit vessel versus multivessel intervention at the time of primary percutaneous coronary intervention in patients with ST-segment-elevation myocardial infarction and multivessel disease: real-world analysis of 3984 patients in London. Circ Cardiovasc Qual Outcomes. 2014;7:936-43.

13. Thygesen K, Alpert JS, Jaffe AS, et al. Third universal definition of myocardial infarction. J Am Coll Cardiol. 2012;60:1581-98.

14. O'Gara PT, Kushner FG, Ascheim DD, et al. 2013 ACCF/AHA guideline for the management of ST-elevation myocardial infarction: a report of the American College of Cardiology Foundation/ American Heart Association Task Force on Practice Guidelines. J Am Coll Cardiol. 2013;61:e78-140.

15. Gershlick AH, Khan JN, Kelly DJ, et al. Randomized trial of complete versus lesion-only revascularization in patients undergoing primary percutaneous coronary intervention for STEMI and multivessel disease: the CvLPRIT trial. J Am Coll Cardiol. 2015;65:963-72.

16. Nguyen JT, Berger AK, Duval S, et al. Gender disparity in cardiac procedures and medication use for acute myocardial infarction. Am Heart J. 2008; 155:862-8.

17. Jneid H, Fonarow GC, Cannon CP, et al. Sex differences in medical care and early death after acute myocardial infarction. Circulation. 2008;118:2803-10.

18. Gevaert SA, De Bacquer D, Evrard P, et al. Renal dysfunction in STEMI-patients undergoing primary angioplasty: higher prevalence but equal prognostic impact in female patients; an observational cohort study from the Belgian STEMI registry. BMC Nephrol. 2013;14:62.

19. Mehilli J, Kastrati A, Dirschinger J, et al. Sex-based analysis of outcome in patients with acute myocardial infarction treated predominantly with percutaneous coronary intervention. JAMA. 2002;287:210-5.
20. Bufe A, Wolfertz J, Dinh W, et al. Gender-based differences in long-term outcome after ST-elevation myocardial infarction in patients treated with percutaneous coronary intervention. J Womens Health (Larchmt). 2010;19:471-5.

21. den Ruijter H, Pasterkamp G, Rutten FH, et al. Heart failure with preserved ejection fraction in women: the Dutch Queen of Hearts program. Neth Heart J. 2015;23:89-93.

22. Pancholy SB, Shantha GP, Patel T, et al. Sex differences in shortterm and long-term all-cause mortality among patients with ST-segment elevation myocardial infarction treated by primary percutaneous intervention: a meta-analysis. JAMA Intern Med. 2014;174:1822-30.

23. Sjauw KD, Stegenga NK, Engstrom AE, et al. The influence of gender on short- and long-term outcome after primary PCI and delivered medical care for ST-segment elevation myocardial infarction. EuroIntervention. 2010;5:780-7.

24. McNamara RL, Wang Y, Herrin J, et al. Effect of door-to-balloon time on mortality in patients with ST-segment elevation myocardial infarction. J Am Coll Cardiol. 2006;47:2180-6.

25. Velders MA, Boden H, Boven AJ van, et al. Influence of gender on ischemic times and outcomes after ST-elevation myocardial infarction. Am J Cardiol. 2013;111:312-8.

26. Dong M, Guo F, Yang J, et al. Detrimental effects of endogenous oestrogens on primary acute myocardial infarction among postmenopausal women. Neth Heart J. 2013;21:175-80.

27. Vaccarino V, Parsons L, Every NR, et al. Sex-based differences in early mortality after myocardial infarction. National Registry of Myocardial Infarction 2 Participants. N Engl J Med. 1999;341:217-25.

28. Mehilli J, Kastrati A, Dirschinger J, et al. Sex-based analysis of outcome in patients with acute myocardial infarction treated predominantly with percutaneous coronary intervention. JAMA. 2002;287:210-5.

29. Champney KP, Frederick PD, Bueno H, et al. The joint contribution of sex, age and type of myocardial infarction on hospital mortality following acute myocardial infarction. Heart. 2009;95:895-9. 